\title{
Theoretical aspects of the onset of Indian summer monsoon from perturbed orography simulations in a GCM
}

\author{
A. Chakraborty ${ }^{1}$, R. S. Nanjundiah ${ }^{2}$, and J. Srinivasan ${ }^{2}$ \\ ${ }^{1}$ Department of Meteorology, Florida State University, Tallahassee, Florida, USA \\ ${ }^{2}$ Centre for Atmospheric and Oceanic Sciences, Indian Institute of Science, Bangalore 560012, India
}

Received: 3 January 2006 - Revised: 23 June 2006 - Accepted: 6 July 2006 - Published: 13 September 2006

\begin{abstract}
A theory is proposed to determine the onset of the Indian Summer Monsoon (ISM) in an Atmospheric General Circulation Model (AGCM). The onset of ISM is delayed substantially in the absence of global orography. The impact of orography over different parts of the Earth on the onset of ISM has also been investigated using five additional perturbed simulations. The large difference in the date of onset of ISM in these simulations has been explained by a new theory based on the Surface Moist Static Energy (SMSE) and vertical velocity at the mid-troposphere. It is found that onset occurs only after SMSE crosses a threshold value and the large-scale vertical motion in the middle troposphere becomes upward. This study shows that both dynamics and thermodynamics play profound roles in the onset of the monsoon.
\end{abstract}

Keywords. Meteorology and atmospheric dynamics (General circulation; Precipitation; Tropical meterology)

\section{Introduction}

The onset of the Indian summer monsoon (ISM) heralds the beginning of the rainy season over the Indian sub-continent. This onset is known to occur suddenly. Various theories have been put forward to explain the onset of the ISM. The most popular (and perhaps the oldest) is that of land-ocean thermal contrast. Yanai et al. (1992) have proposed that Tibet, as an elevated heat source, plays an important role in the onset of monsoons. Others have suggested alternative theories to explain the onset of monsoon. Kawamura et al. (2002) have suggested that a combination of an increase in sea surface temperatures and dry intrusion in the 600-850-hPa layer over the ocean on the equatorial side of the continent plays an important role in determining the onset. The dry air intrudes

Correspondence to: A. Chakraborty

(arch@io.met.fsu.edu) into the sea, due to the thermal circulation and the SST increases, in turn lead to an increase in the instability (making conditions favorable for onset). In addition, they suggest that an external forcing, such as the Madden-Julian Oscillation (MJO), triggers the onset of monsoon. They show that this mechanism not only explains the onset of the Indian summer monsoon but also the Australian and East Asian monsoons. He et al. (2003) suggest that the reversal of meridional temperature gradient related to diabatic warming and horizontal warm advection is the primary cause of the sudden onset of monsoons.

Fasullo and Webster (2003) have used the vertically integrated moisture transport and developed a Hydrological Onset and Withdrawl Index (HOWI) to determine onset and withdrawal of monsoons. They have shown that their method eliminates "bogus onsets", and unlike the onset definition of the India Meteorological Department, their definition shows a good correlation between the dates of onset and withdrawal, and the strength of the monsoons. Krishnakumar and Lau (1998) have argued that the onset is linked to dry/moist conditional instability of zonal monsoon flow. Yano and McBride (1998) have suggested that onset implies a switch from one dynamical regime to the other, due to seasonally varying Sea Surface Temperature (SST) forcing. Chao (2000) has suggested that onset is related to the subcritical instability from the equatorial trough flow regime to the monsoon trough flow regime. Xie and Saiki (1999) hypothesize that the delay in formation of direct circulation (related to geostrophic balance) and moist static stability is responsible for the sudden changes associated with the onset of monsoon. Kanae et al. (2002) have studied the onset of Asian summer monsoon and suggest that warm SST around Indochina is a prerequisite for onset. Minoura et al. (2003) have attempted to validate the mechanism of onset proposed by Kawamura et al. (2002) over the South Asian region using the European Centre for Medium Range Weather Forecasts (ECMWF) analysis.

Published by Copernicus GmbH on behalf of the European Geosciences Union. 
Table 1. Nomenclature for different perturbed orography simulations and the total number of integrations performed in each experiment including the control simulations with two different cumulus parameterization schemes. For some simulations one member of the ensemble was integrated for 63 months (5.25 years). These are identified as parenthesized (5-yr) in the table.

\begin{tabular}{llcc}
\hline Name & Description & \multicolumn{2}{c}{ Ensemble size with } \\
& & SAS Conv. & Kuo Conv. \\
\hline Control & $\begin{array}{l}\text { Standard simulation } \\
\text { with mean orography }\end{array}$ & $25(5-\mathrm{yr})$ & $10(5-\mathrm{yr})$ \\
\hline noGlOrog & $\begin{array}{l}\text { No orography all } \\
\text { over the globe }\end{array}$ & $12(5-\mathrm{yr})$ & $5(5-\mathrm{yr})$ \\
\hline noEhOrog & $\begin{array}{l}\text { No orography between } \\
80^{\circ}-120^{\circ} \mathrm{E}, 0-60^{\circ} \mathrm{N}\end{array}$ & 5 & 5 \\
\hline noWhOrog & $\begin{array}{l}\text { No orography between } \\
60^{\circ}-80^{\circ} \mathrm{E}, 25^{\circ}-60^{\circ} \mathrm{N} .\end{array}$ & $5(5-\mathrm{yr})$ & 5 \\
\hline noAfOrog & $\begin{array}{l}\text { No orography over } \\
\text { the African continent. }\end{array}$ & 5 & 1 \\
\hline prAfOrog & $\begin{array}{l}\text { Orography present only } \\
\text { over Africa }\end{array}$ & 5 & 0 \\
\hline noAmOrog & $\begin{array}{l}\text { No orography over } \\
\text { the Americas }\end{array}$ & 5 & 0 \\
\hline
\end{tabular}

This paper attempts to study the onset of the monsoon in a General Circulation Model (GCM) and to develop a theory for the mechanism of onset. The onset of monsoons is associated with the occurrence of a strong heat source and substantial changes in circulation. Hence, a theory of monsoon onset should consider both dynamic and thermodynamic effects. A study of this kind needs the dates of onset to be varied substantially. However, if one analyzes observations (or data sets, such as NCEP/NCAR reanalysis or the ECMWF reanalysis), one finds that the onset dates do not vary dramatically (as the mean onset date over Kerala is 1 June, with a standard deviation of 7 days). Hence, it is difficult to test different hypotheses about the onset of the monsoon from observational data. However, we have tested the theory proposed here for two years of observed data when the all-India monsoon onset date differs by 29 days.

Previous studies, such as that of Hahn and Manabe (1975), show that modification of orography substantially changes the monsoons. Hence, we perturb the orography in the environs of the Indian sub-continent and elsewhere to alter the dates of onset. This can alter the date of onset by as much as 57 days. Based on this we propose a theory to explain the onset of monsoon. It is to be noted that by onset we imply the occurrence of persistent rainfall over the entire Indian landmass and not the occurrence of rainfall over a small subregion (such as the state of Kerala).

In the next two sections we describe the model and the numerical experiments conducted. The control simulation of the model is compared with the satellite-based estimates in Sect. 4. Section 5 discusses the impact of global orography on the onset of the Indian monsoon. The cause of delay and a hypothesis to explain the onset is presented in Sect. 6 . The relative importance of Eastern and Western Himalayan orography in modulating the onset is discussed in Sect. 7. The hypothesis is further verified by perturbing the African and American orography in Sects. 8 and 9. Section 10 tests the results with a different convection scheme and for the observational-based data sets. This is followed by Discussions and Conclusions.

\section{Model description}

The global atmospheric GCM used in this study is a version of the of the National Meteorological Centre (NMC, now NCEP) global spectral model (Sela, 1988), with a triangular truncation at 80 waves (T-80), which corresponds to 128 global Gaussian grids in the north-south direction (resolution $\sim 1.41^{\circ}$ ) and 256 equally spaced grids in the east-west direction (resolution $\sim 1.41^{\circ}$ ). It has 18 vertical sigma levels, with more closely spaced levels near the surface. The Simplified Arakawa-Schubert (SAS) scheme (Grell, 1993) was used for convection parameterization. With a view to understand the robustness of the simulations we also conducted another ensemble of simulations using the Kuo cumulus parameterization scheme (Anthes, 1977). The model's shortwave radiation scheme was from Lacis and Hansen (1974) and the longwave radiation scheme was used from Fels and Schwarzkopf 


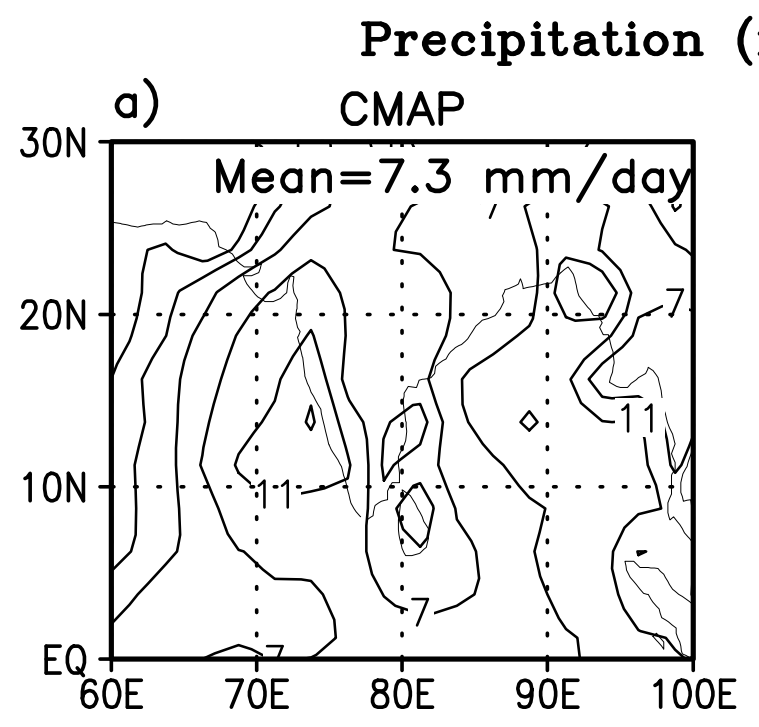

\section{(mm/day), JJAS98}

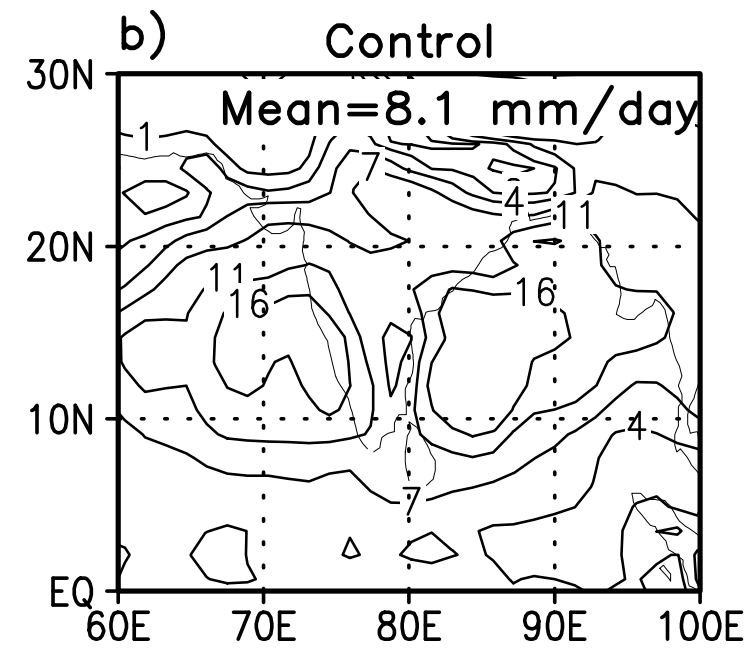

Fig. 1. Precipitation rate (in mm day ${ }^{-1}$ ) over the South Asian monsoon region during June-September 1998 from CMAP (Xie and Arkin, 1997) and the ensemble mean of the control simulations of the NCMRWF model. Contour are drawn at 1, 2, 4, 7, 11 and 16 mm day ${ }^{-1}$ levels. The domain averaged values are indicated at the top-right corner of the respective panels.

(1981). It uses a simple one-layer bucket model for surface hydrology calculation (Pan and Mahrt, 1986). The gravity wave drag parameterization was taken from Pierhumbert (1987). The model's ability to simulate the Indian summer monsoon and the impact of Asian and African orography on its strength has been studied by Chakraborty et al. (2002).

\section{Experimental details}

We have conducted seasonal simulations with the NCMRWF model. To reduce the impact of initial conditions we have conducted ensemble simulations with 5 different initial conditions from NCEP/NCAR reanalysis (Kalnay et al., 1993), corresponding to 00:00 UTC on 1-5 March 1998. SST was specified by interpolating the monthly mean values for 1998 from Reynolds and Smith (1995) to the model run time. In both the control and the perturbed experiments mean orography from NCEP/NCAR reanalysis data set was used. The ensemble mean results are presented in this paper.

In this paper we have studied the factors that govern the date of onset of the Indian summer monsoon. This has been done by changing the orography in the vicinity of the Indian landmass, over the American region and by removing the orography over the entire globe. The details of the simulations conducted are given in Table 1.

In the perturbed runs, when orography was removed, the land elevation was reduced to the mean sea-level but the initial conditions for surface pressure for the perturbed simulations were kept identical to those in the control experiments. To understand the impact of initial conditions on surface pressure, we conducted simulations in which the model was started from a state of rest (and constant surface pressure equal to its globally averaged value in the NCEP/NCAR Reanalysis). We found that the simulations were largely insensitive to these initial conditions (Kitoh, 2002, has also arrived at a similar conclusion in their coupled simulations). Hence, we have used identical initial conditions for both control and sensitivity simulations.

We have also conducted a five-year simulation for one of the ensemble members and found that the precipitation pattern averaged over the five summers was very similar to the ensemble mean. The onset dates for the five-year run show a variation very similar to that in the ensemble run. However, since the major objective of the present paper is to study the onset of the Indian monsoon, we have used the ensemble technique. All results shown are for the ensemble mean.

\section{Precipitation from control simulation}

The validity of perturbed simulations can be justified only if the control simulation of a model captures the broad feature that is observed in the nature. Figure 1 compares the precipitation from control simulations and that from the satellitebased estimates of CMAP (Xie and Arkin, 1997) during June-September of 1998. Note that the control simulation of the model could capture the overall spatial distribution of satellite estimated precipitation over this region. The high precipitation near the west coast of the Western Ghats mountains and low precipitation over the northern parts of the Indian land mass are well captured by the model. But the model could not capture the high precipitation region near the northern Bay of Bengal. The domain averaged precipitation from 
Table 2. Table showing the monthly mean precipitation in control, noGlOrog, noEhOrog and noWhOrog simulations. The values in parentheses indicates the significance level at which the perturbed simulations differ from control using a paired t-test.

\begin{tabular}{cllll}
\hline Month & control & noGlOrog & noEhOrog & noWhOrog \\
\hline June & 4.5 & $1.8(99.6 \%)$ & $3.7(92 \%)$ & $2.3(98 \%)$ \\
\hline July & 7.6 & $3.3(99.7 \%)$ & $6.6(99 \%)$ & $5.1(99 \%)$ \\
\hline Aug & 7.8 & $7.2(19.2 \%)$ & $6.7(80 \%)$ & $6.9(44 \%)$ \\
\hline Sep & 5.9 & $6.7(93.6 \%)$ & $5.4(95 \%)$ & $5.5(95 \%)$ \\
\hline
\end{tabular}

the control simulation $\left(8.1 \mathrm{~mm} \mathrm{day}^{-1}\right)$ was very close to that of the CMAP $\left(7.3 \mathrm{~mm} \mathrm{day}^{-1}\right)$ value. Therefore, the control simulation was able to capture the overall feature of the South Asian monsoon during the summer months of 1998.

\section{Global orography and the Indian summer monsoon}

Table 2 shows the monthly mean precipitation from June to September over the Indian region $\left(68.2^{\circ}-90.7^{\circ} \mathrm{E}, 8.4^{\circ}-\right.$ $28.0^{\circ} \mathrm{N}$, land part) with (control) and without (noGlOrog) orography. We find that the precipitation is much lower during the months of June and July in the absence of orography but it is comparable to that of the control during the months of August and September. The differences during the months of June and July are significant over the 99\% level (using a paired t-test), while the differences during August and September are not significant. The ensemble-mean daily time series of the control and noGlOrog simulations (Fig. 2) show that the rainfall in the two simulations is similar during May, much higher in the control during June and July and comparable in August and September. This shows a delay in the onset of monsoon over the Indian region in the absence of orography. As noted earlier, the purpose of our study is to study the onset over the Indian landmass and not just onset over a sub-region, such as the state of Kerala. Therefore, we define the onset in our model simulation as "the first day of the monsoon season when the precipitation rate exceeds $4.0 \mathrm{~mm} \mathrm{day}^{-1}$ over the Indian region and remains above this value for at least five consecutive days." This criterion for defining, the onset is very similar to that used by Wang and LinHo (2002) and Janowiak and Xie (2003). Using this definition we find that the onset date in the control is 19 June and $28 \mathrm{July}$ in noGlOrog, i.e. the onset is delayed by about 39 days in the absence of orography (Fig. 2). Interestingly, we also find that after the onset occurs, the rainfall in the two simulations are quite similar. The presence of orography thus appears to play an important role in determining the date of onset of the Indian Summer Monsoon Rainfall (ISMR), but after onset the dynamics and thermodynamics appear to

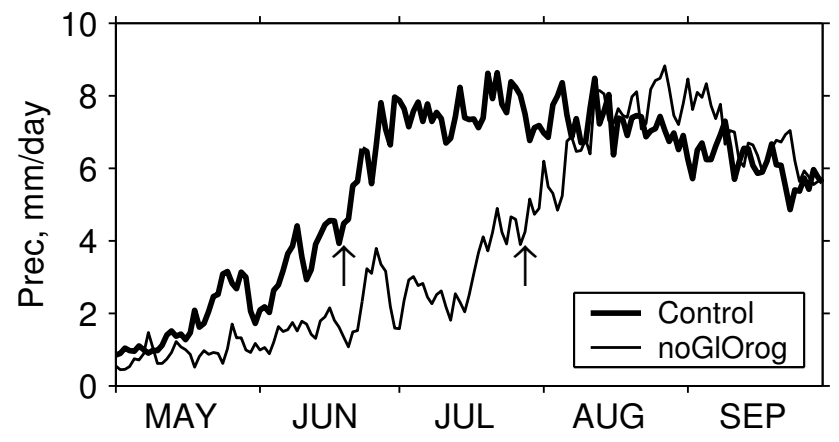

Fig. 2. Daily rainfall variation over the Indian region from the control and noGlOrog simulations in $\mathrm{mm} \mathrm{day}^{-1}$. Monsoon onset dates in both simulations (obtained according the definition of onset used in this study, see Sect. 5 of text for details) are indicated by arrows in the corresponding curves. The onset of monsoon over this region was delayed by 39 days when orography was removed from the entire globe.

play a more important role in determining the strength of the monsoon rainfall, in agreement with the results of Hoskins and Rodwell (1995). Note that the withdrawal phase of the monsoons in September is largely unaffected by the presence of orography. The relatively shorter length of the season thus causes the rainfall in noGlOrog to be lower by about $25 \%$ (which is related to the delay in the onset). Thus, having established that changes in orography lead to a change in the onset date and that during the post-onset phase the effect of orography is secondary, we examine the cause of this delay in the onset of the monsoons.

\section{What determines the date of the onset of the mon- soon?}

Large-scale organized convection, such as the Indian summer monsoon rainfall, is associated with reduced vertical static stability. Two frequently used parameters for measuring the atmospheric stability are the Gross Moist Stability (GMS) and Vertical Moist-static Stability (VMS). Nanjundiah and Srinivasan (1999) have shown that VMS and precipitation in the tropics are related to GMS. However, these indices are only useful on a monthly mean-scale. While studying variations on the daily scale, Convective Available Potential Energy (CAPE) is a useful measure of vertical moist instability (Iribarne and Godson, 1973). Another useful measure of instability is the Moist Static Energy (MSE) of the surface layer (Surface Moist Static Energy or SMSE) and is defined as

$$
\begin{aligned}
M S E & =C_{p} T+g z+L_{c} q \\
& =D S E+T_{q},
\end{aligned}
$$

where $D S E$ is the dry static energy $\left(=C_{p} T+g z\right)$ and $T_{q}$ is the moisture term $\left(L_{c} q\right)$ of the MSE equation. Figure 3 shows 


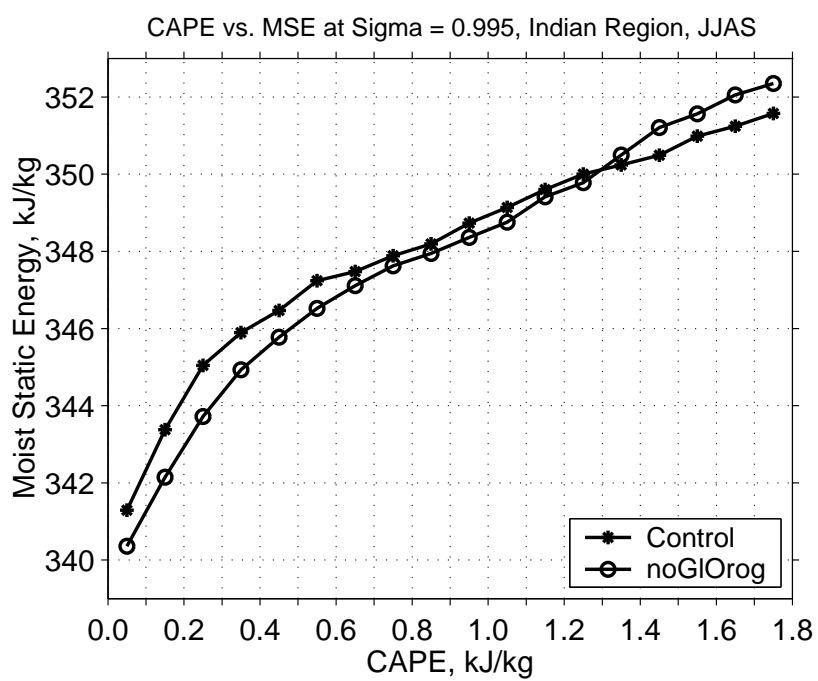

Fig. 3. Relation between convective available potential energy (CAPE) and surface moist static energy (SMSE, the moist, static energy at the model's bottom most sigma layer: $\sigma=0.995$ ) over the Indian region from the control and noGlOrog simulations. CAPE values were grouped at $0.1 \mathrm{~kJ} \mathrm{~kg}^{-1}$ bins and all the SMSE values corresponding to those grids were averaged for clarity of presentation. The rate of increase of SMSE with CAPE is higher for SMSE values below $346 \mathrm{~kJ} \mathrm{~kg}^{-1}\left(\mathrm{CAPE}<0.4 \mathrm{~kJ} \mathrm{~kg}^{-1}\right)$ as compared to the rate when SMSE is higher than $346 \mathrm{~kJ} \mathrm{~kg}^{-1}$. Note that this relationship between CAPE and SMSE is independent of the presence of orography.

the relation between SMSE and CAPE over the Indian region for the June-September season, from control and noGlOrog simulations. CAPE and SMSE of the model layer $\sigma=0.995$ (closest to the surface) were calculated during all 122 days of this season. For clarity of presentation, CAPE values were binned to $0.1-\mathrm{kJ} \mathrm{kg}^{-1}$ intervals and all SMSE values corresponding to those grids were averaged to obtain the mean SMSE in that interval of CAPE. The result shows that CAPE and SMSE over the Indian region are related on a daily scale during the summer monsoon period. CAPE becomes positive and increases rapidly only after SMSE reaches a value of about $346 \mathrm{~kJ} \mathrm{~kg}^{-1}$. We also note that the relationship between CAPE and SMSE is very similar for the noGlOrog and the control simulations. Therefore SMSE can be used as a yardstick of vertical stability on a daily scale. Examining the temporal variation of SMSE over the Indian region (Fig. 4) we notice that the onset occurs in both simulations, a little after SMSE reaches the threshold value of $346 \mathrm{~kJ} \mathrm{~kg}^{-1}$. We also notice that while in the control SMSE reaches the threshold value in early June, in the noGlOrog it reaches it in late July, approximately 50 days later.

We now examine the various components of Eq. 1 to find their contributions for the change in MSE for control and noGlOrog simulations. We find that the moisture term $\left(T_{q}\right)$

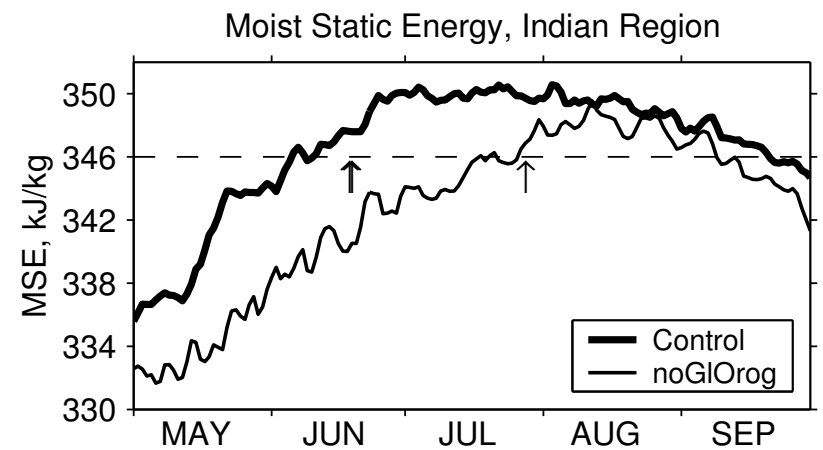

Fig. 4. Surface Moist Static Energy (SMSE) over the Indian region from the control and noGlOrog simulations. The onset dates obtained from the precipitation criteria are marked by arrows against each time series. Note that SMSE crosses the threshold of $346 \mathrm{~kJ} \mathrm{~kg}^{-1}$ over this region a few days before the onset of precipitation in the respective simulations.
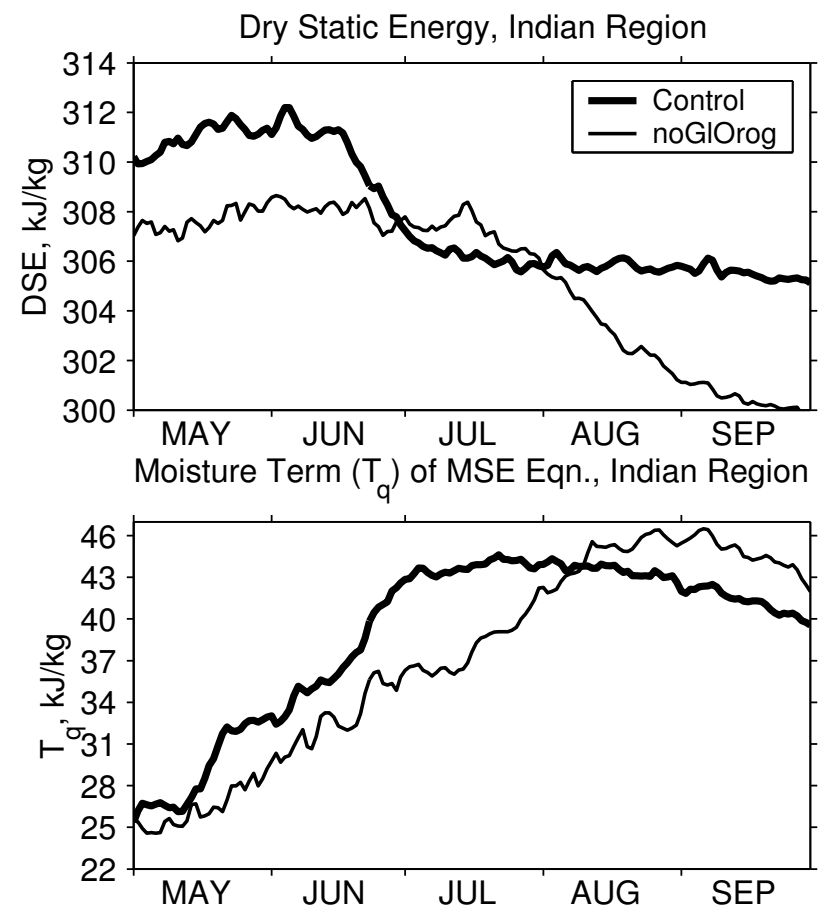

Fig. 5. Surface dry static energy (DSE) and moisture term of the moist static energy equation $\left(\mathrm{T}_{q}\right)$ over the Indian region from the control and noGlOrog simulations.

is the major contributor (Fig. 5). We also find that $T_{q}$ was comparable in the two simulations in early May but rapidly increased in the control during the later part of May. The two values again became comparable in August and remained so for the rest of the season. In contrast, DSE was substantially lower throughout the season (except during July when they were comparable) in the noGlOrog simulation. The lower 
$D S E$ was on account of lower temperatures due to the advection of colder air from higher latitudes. This is illustrated in Fig. 6. In this figure shading shows a negative gradient of air temperature at $925 \mathrm{hPa}$, signifying more cold air toward the north. In the noGlOrog simulation air temperature decreases north of $22^{\circ} \mathrm{N}$. This, along with a strong southward flow $\left(\sim 4 \mathrm{~m} \mathrm{~s}^{-1}\right)$, advects cold air and reduces DSE of lower the troposphere over the Indian region. Therefore, to reach the threshold SMSE $\left(\sim 346 \mathrm{~kJ} \mathrm{~kg}^{-1}\right)$ that would make the atmosphere amenable to convection, noGlOrog had to overcome the larger deficit in $D S E$ which took longer and delayed the onset of convection. In the post-onset period, $D S E$ reduces, due to the evaporative cooling effect close to the surface. We note that the cold-air advection from mid-latitudes is more prominent west of $80^{\circ} \mathrm{E}$, than east of $80^{\circ} \mathrm{E}$ even in the noGlOrog simulations.

If moisture advection were to be the sole criteria, then a hydrological variable, such as the vertically integrated precipitable water $\left(\mathrm{P}_{\mathrm{wat}}\right)$, would be a necessary and sufficient condition for determining the onset. When we examine the evolution of $\mathrm{P}_{\text {wat }}$ we find that the onset in the control occurs when $P_{\text {wat }}$ reaches a value of about $45 \mathrm{~kg} \mathrm{~m}^{-2}$ (Fig. 7). However, in the noGlOrog though $\mathrm{P}_{\text {wat }}$ reaches this value in the middle of June, the onset occurs about a month later. This clearly suggests that a hydrological variable alone may be an insufficient criteria for the onset. We also compare the relationship between CAPE and $\mathrm{P}_{\text {wat }}$ (Fig. 8) in the control and noGlOrog simulations and find that for a given value of $\mathrm{P}_{\mathrm{wat}}$, CAPE is lower in the noGlOrog simulation, i.e. the atmosphere in noGlOrog is more stable for a given value of $\mathrm{P}_{\text {wat }}$. This is consistent with the evolution of DSE, which shows that the noGlOrog is more dry and statically stable and thus an additional amount of moisture is required to trigger the onset. As shown above, the atmosphere in the noGlOrog is more stable due to advection of cold air into the region. Therefore, a hydrological conditioning parameter alone might be insufficient and a parameter such as SMSE, based both on hydrology and thermodynamics and whose threshold is the same for both, control and noGlOrog might, be more useful parameter to determine onset.

\section{Cumulus parameterization, orography and delay in onset}

The results discussed above were with simulations using the SAS scheme. Since monsoon and its onset are phenomena dominated by organized convection, it is necessary to check the results for sensitivity to cumulus convection. Hence, we repeated the experiments (for both control and noGlOrog) with the Kuo-Anthes parameterization scheme, (Anthes, 1977). The results were similar to that of the SAS scheme i.e. the precipitation over the Indian region in the JJAS season was lower in the absence of orography and this lower precipitation was related to the delay in the onset of the monsoon. The rainfall in the noGlOrog simulation with the Kuo scheme was lower in June and July (the difference

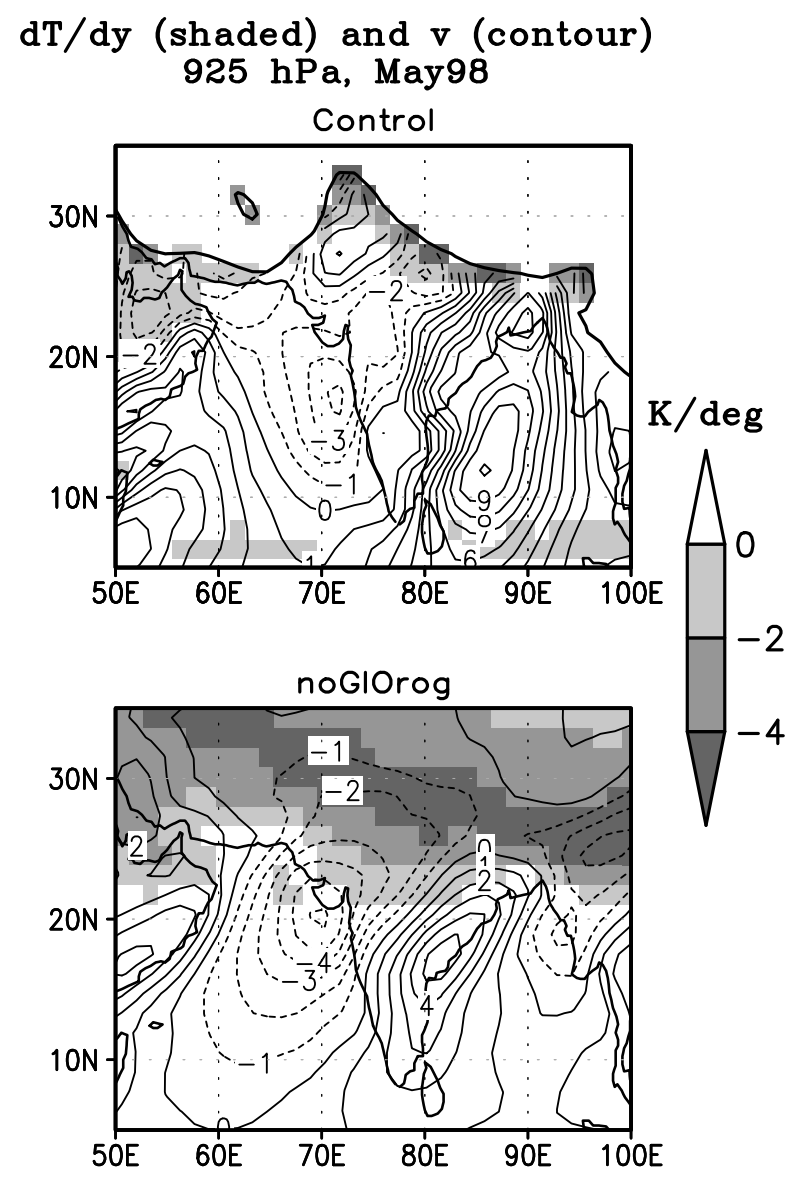

Fig. 6. Meridional gradient of air temperature (shaded) and meridional velocity (contour) at $925 \mathrm{hPa}$ in the control and noGlOrog simulations during May. In the noGlOrog simulation, a negative northsouth gradient of air temperature (signifies more cold air toward north), along with a southward flow, advects cold air and reduces the dry static energy over the Indian region. This advection is most prominent west of $80^{\circ} \mathrm{E}$.

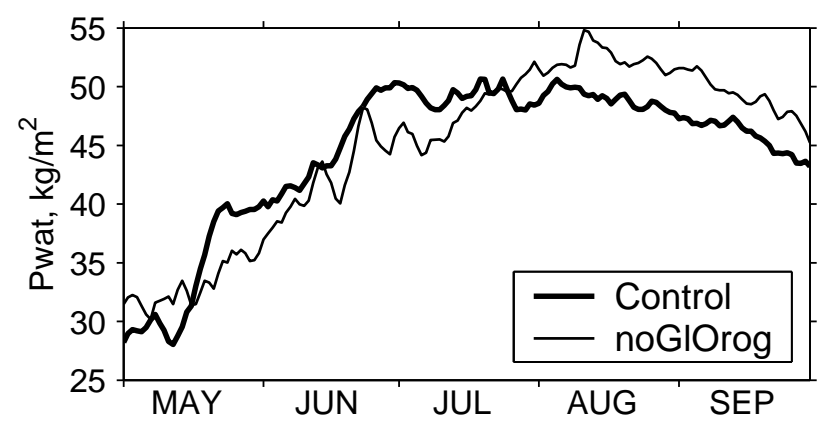

Fig. 7. Evolution of $\mathrm{P}_{\text {wat }}\left(\mathrm{kg} \mathrm{m}^{-2}\right)$ over the Indian region in control and noGlOrog simulations. 


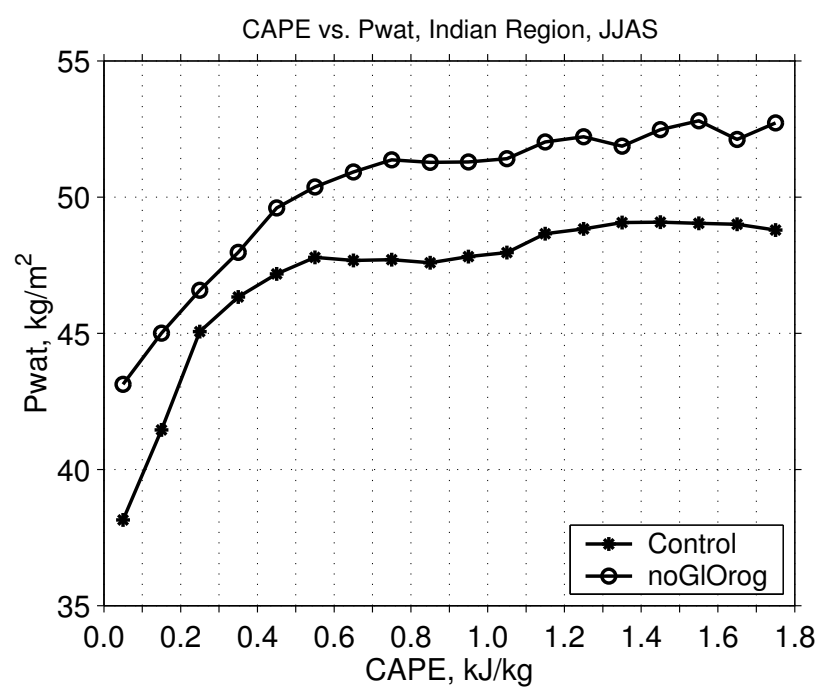

Fig. 8. Relation between convective available potential energy (CAPE) and total column precipitable water $\left(\mathrm{P}_{\text {wat }}\right)$ over the Indian region from the control and noGlOrog simulations. Note that for CAPE values below $0.4 \mathrm{~kJ} \mathrm{~kg}^{-1}$ the rate of increase of $P_{\text {wat }}$ with CAPE is higher in the control as compared to the noGlOrog. This is unlike the SMSE-CAPE relationship shown in Fig. 3. Thus, the relationship between CAPE and $\mathrm{P}_{\text {wat }}$ does depend on the presence of orography.

was significant over $99.0 \%$ the confidence level) but comparable in August and September. Hence, further simulations to study the impact of orography over various regions of the world on monsoon onset have been conducted with the SAS scheme alone.

\section{Effect of Himalayan orography}

We have seen in Sect. 5 that orography has a significant impact on the onset of the Indian summer monsoon. Since one of the largest mountain ranges, the Himalayas, is in the neighborhood of the Indian region, it is not surprising that it would have a significant impact on the monsoons.

The Himalayas and associated mountain ranges can broadly be classified into distinct regions, viz. the Tibetan plateau and associated mountains to the east of $80^{\circ} \mathrm{E}$ and mountains to the west of $80^{\circ} \mathrm{E}$. As noted earlier, we find that the advection of cold-air from mid-latitudes in the absence of orography (Fig. 6) is more noticeable west of $80^{\circ} \mathrm{E}$. Hence to understand the role of the West Himalayan and East Himalayan orography separately, we conducted simulations with orography removed (over the Asian region) east of $80^{\circ} \mathrm{E}$ (noEhOrog simulation) and with orography removed (over the Asian region) west of $80^{\circ} \mathrm{E}$ (noWhOrog simulation). Here we discuss the role of Eastern and Western Himalayas on the onset of the Indian Summer Monsoon.
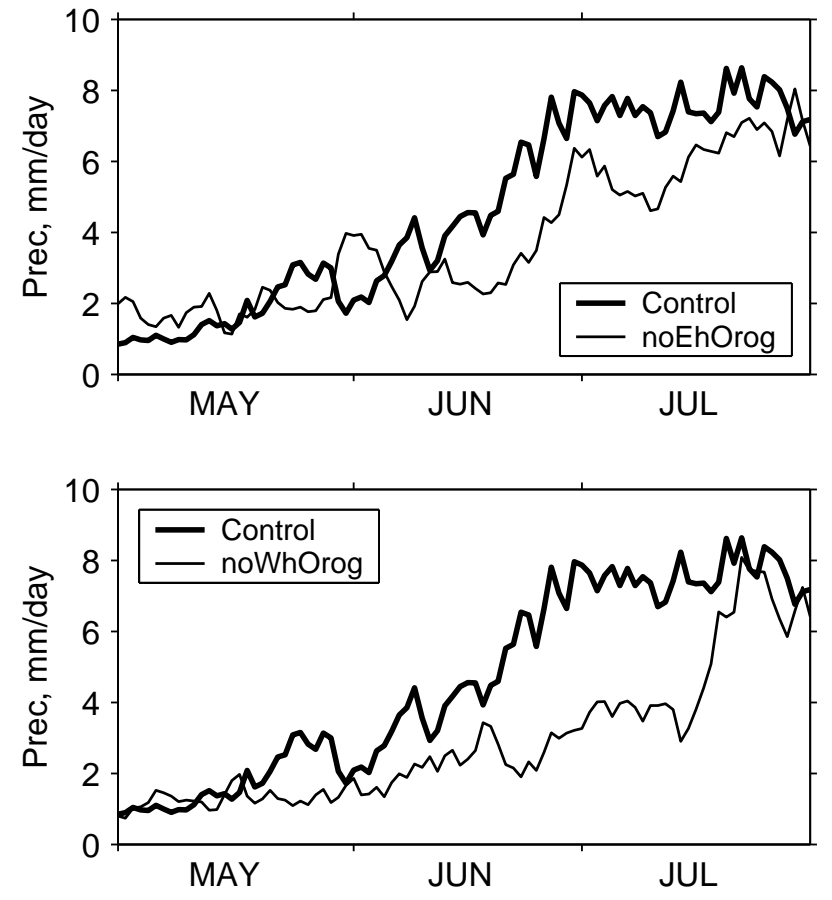

Fig. 9. Evolution of rainfall over Indian region in the control, noWhOrog and noEhOrog simulations.

Table 2 shows that rainfall during June and July was substantially reduced in the absence of west Himalayan orography (noWhOrog) and is affected to a lesser extent by the absence of the East Himalayan orography (noEhOrog); the rainfall during June and July is higher in the noEhOrog visa-vis noWhOrog.

From the daily time series of area-averaged precipitation in control, noEhOrog and noWhOrog (Fig. 9) we notice that the onset in noWhOrog was considerably delayed while the delay was less in the case of noEhOrog. However, we find that the delay was not uniform over all parts of the Indian sub-continent. This is illustrated in Fig. 10, which shows the daily rainfall over West Central India $\left(70^{\circ}-80^{\circ} \mathrm{E}\right.$, $15^{\circ}-25^{\circ} \mathrm{N}$, WCI) and over North East India $\left(90^{\circ}-100^{\circ} \mathrm{E}\right.$, $\left.23^{\circ}-33^{\circ} \mathrm{N}, \mathrm{NEI}\right)$. We note that while the absence of East Himalayan orography does not have much of an impact on WCI rainfall, it has a significant impact on the NEI rainfall. Conversely, the absence of West Himalayan orography has a larger impact on WCI rainfall than on NEI rainfall. However, considering the entire Indian landmass, we find that the onset is delayed by over a month in the noWhOrog simulation, and was affected minimally in the noEhOrog simulation. The reason for this is discussed below. 

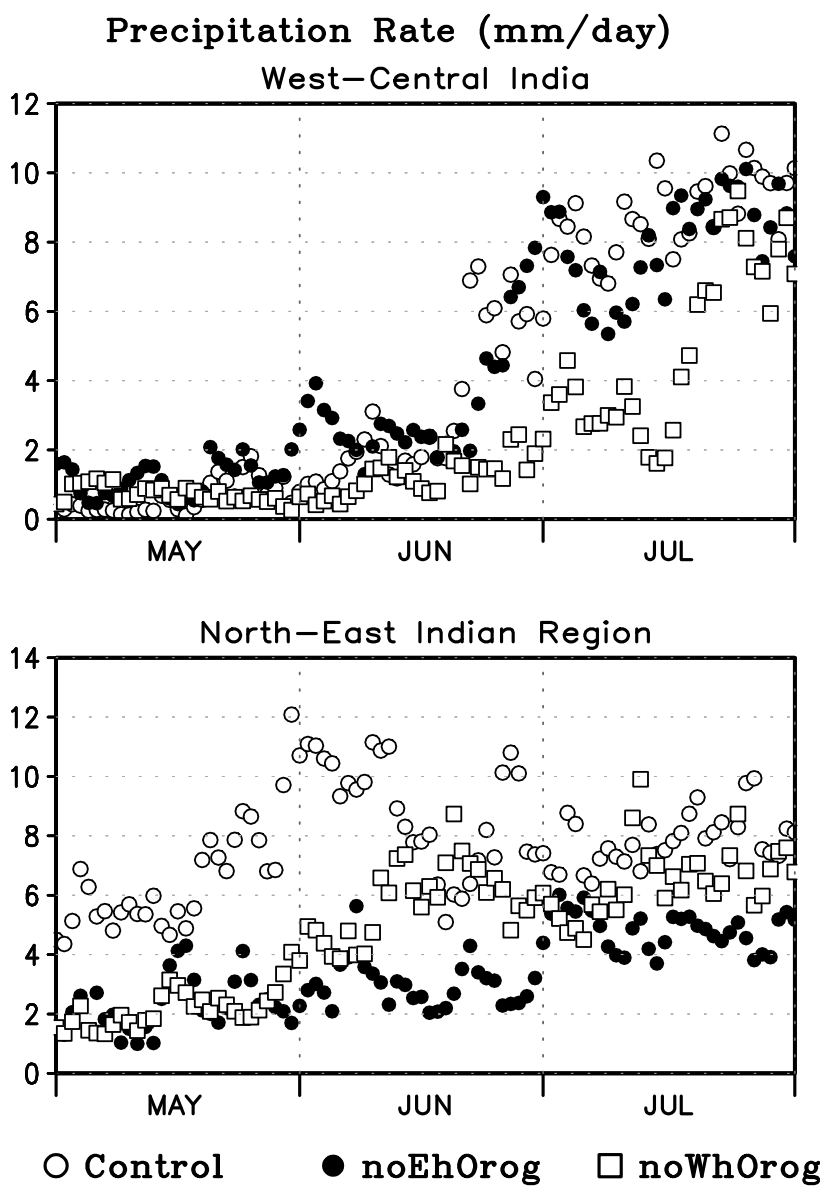

Fig. 10. Evolution of rainfall over (top) West Central India (WCI) and (bottom) North East India (NEI) in the control, noWhOrog and noEhOrog simulations.

\section{Delay of onset in the absence of West Himalayan orography}

The cause of delay in the onset in the noGlOrog simulation was found to be related to the atmosphere being more stable, on account of colder temperatures and lower moisture and hence the threshold value of MSE was reached later and consequently, the onset was delayed. In the daily variation of SMSE (Fig. 11), we find that SMSE in the control and noEhOrog reached the threshold value almost simultaneously in the middle of June, while the noWhOrog simulation reached the threshold value about 3 weeks later. As in noGlOrog, a cooler and drier lower troposphere caused the SMSE to be lower in the noWhOrog simulation.

We compare next the impact of removing orography over these regions on mid-latitude cold air advection over the Indian subcontinent. We have studied the vertical variation of meridional velocity and meridional advection of energy $\left(v \frac{\partial T}{\partial y}\right)$ in the longitude belts $65^{\circ}-75^{\circ} \mathrm{E}$ for the noWhOrog and

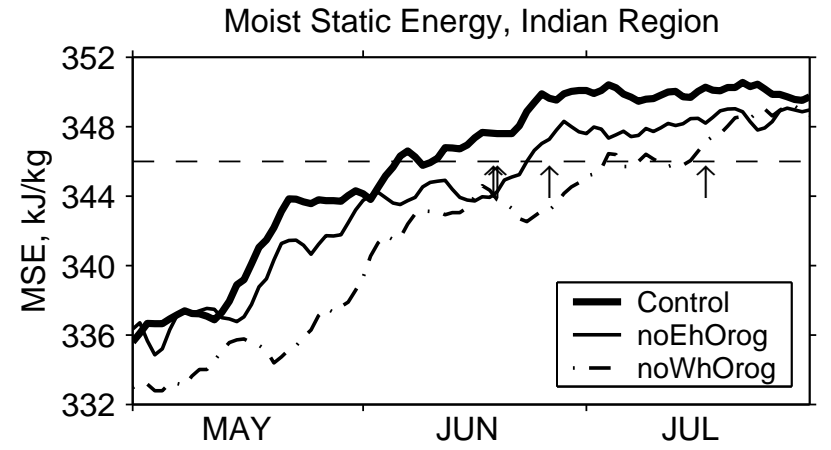

Fig. 11. Evolution of SMSE over the Indian region in the control, noWhOrog and noEhOrog simulations.

$85^{\circ}-95^{\circ} \mathrm{E}$ for the noEhOrog simulation (Figs. 12, 13). The orography was removed over these regions for those respective simulations. We notice that the meridional velocities in the noWhOrog are southward up to about $700 \mathrm{hPa}$ (Fig. 12b), while the meridional velocities are largely northward in the "gap" (i.e. region where orography has been removed) for noEhOrog (Fig. 13b). Additionally, the meridional gradient of temperature was much stronger (i.e. colder to the north) in noWhOrog and hence advection of cold air more pronounced (Fig. 12: $v \frac{\partial T}{\partial y}$ is positive in the noWhOrog, as both meridional velocity $v$ and the gradient of temperature $\frac{\partial T}{\partial y}$ are negative). The southward flow in the lower troposphere, coupled to the stronger meridional gradient in the noWhOrog simulation caused the cold air to be advected into the Indian region from the mid-latitudes.

\section{Role of African orography}

Having examined the orography in the proximity of the Indian region, we now study the impact of orography over more remote regions, viz. African orography. The mountains of Africa and their impact on the Somali jet have been the focus of many studies (Krishnamurti et al., 1976; Sashegyi and Geisler, 1987, and many other studies). Most of these studies have been with linear models with prescribed forcing. The analysis of these results indicate that the Somali jet (and consequently the Indian monsoon) would weaken in the absence of African orography. However, a GCM study by Chakraborty et al. (2002) shows that the strength of the ISMR increases in the absence of African orography (Fig. 14a). The cause of this strengthening is two-fold: (a) larger mass convergence into the Indian region due to the removal of African mountain barrier. The larger mass convergence was possible due to the removal of the East African orography that acts as a barrier at the lower level. In the absence of this barrier and a similar strong heat source over the Indian region, as that in the control run, the 


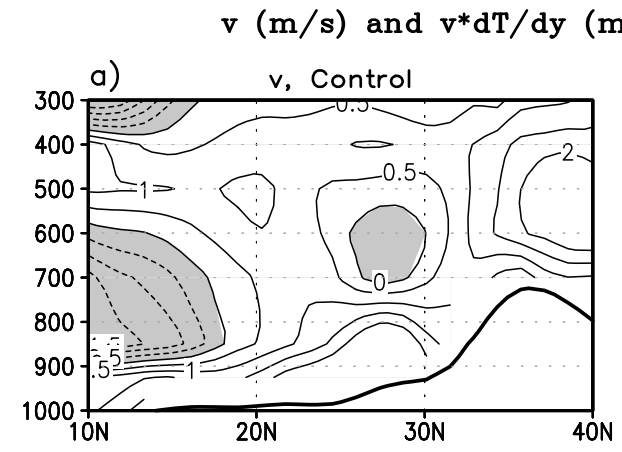

$\left(\mathrm{m} \mathrm{K} \mathrm{s}^{-1} \mathrm{deg}^{-1}\right), 65-75 \mathrm{E}$, JUL98
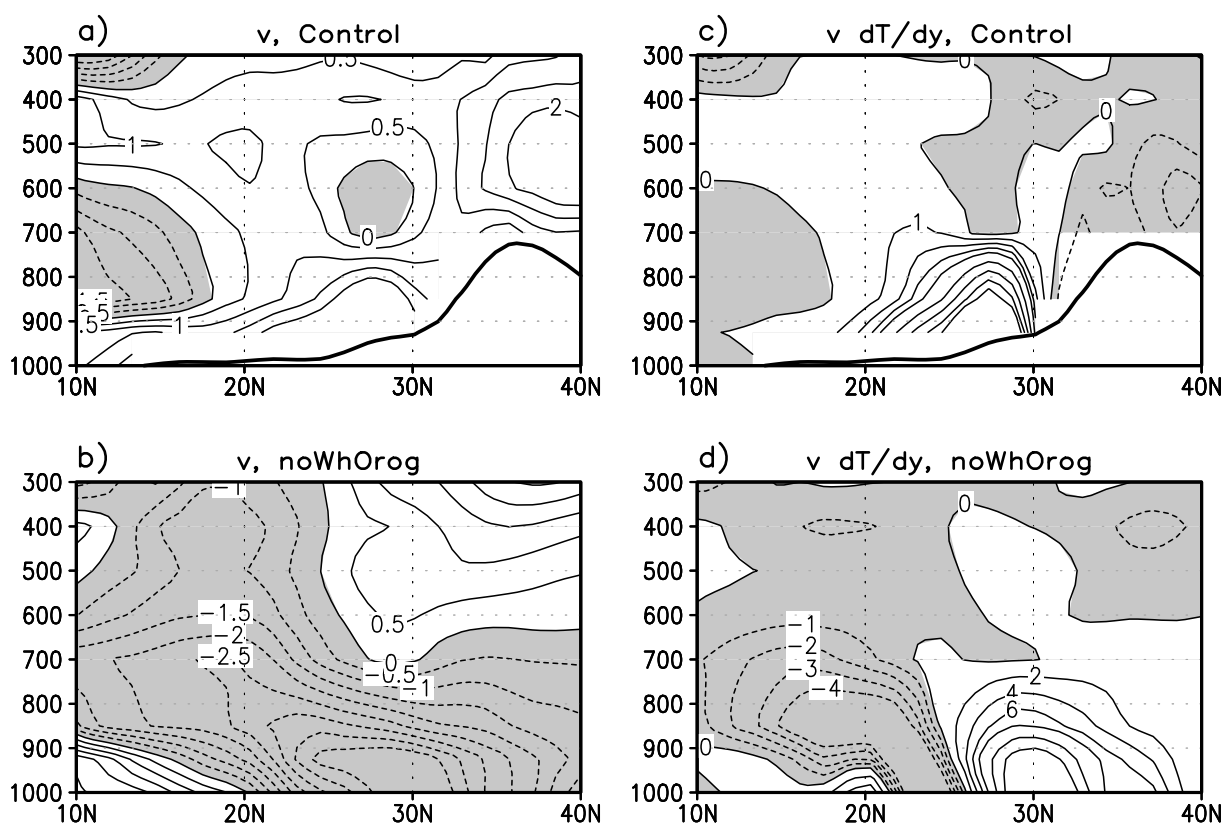

Fig. 12. Vertical profile of meridional velocity from the(a) control and (b) noWhOrog simulations, averaged between $65^{\circ}-75^{\circ} \mathrm{E}$. Vertical profiles of temperature (energy) advection from the(c) control and (d) noWhOrog simulations are shown for the same region.

$\mathrm{v}(\mathrm{m} / \mathrm{s})$ and $\mathrm{v}^{*} \mathrm{dT} / \mathrm{dy}\left(\mathrm{m} \mathrm{K} \mathrm{s}^{-1} \mathrm{deg}^{-1}\right)$, 85-95E, JUL98
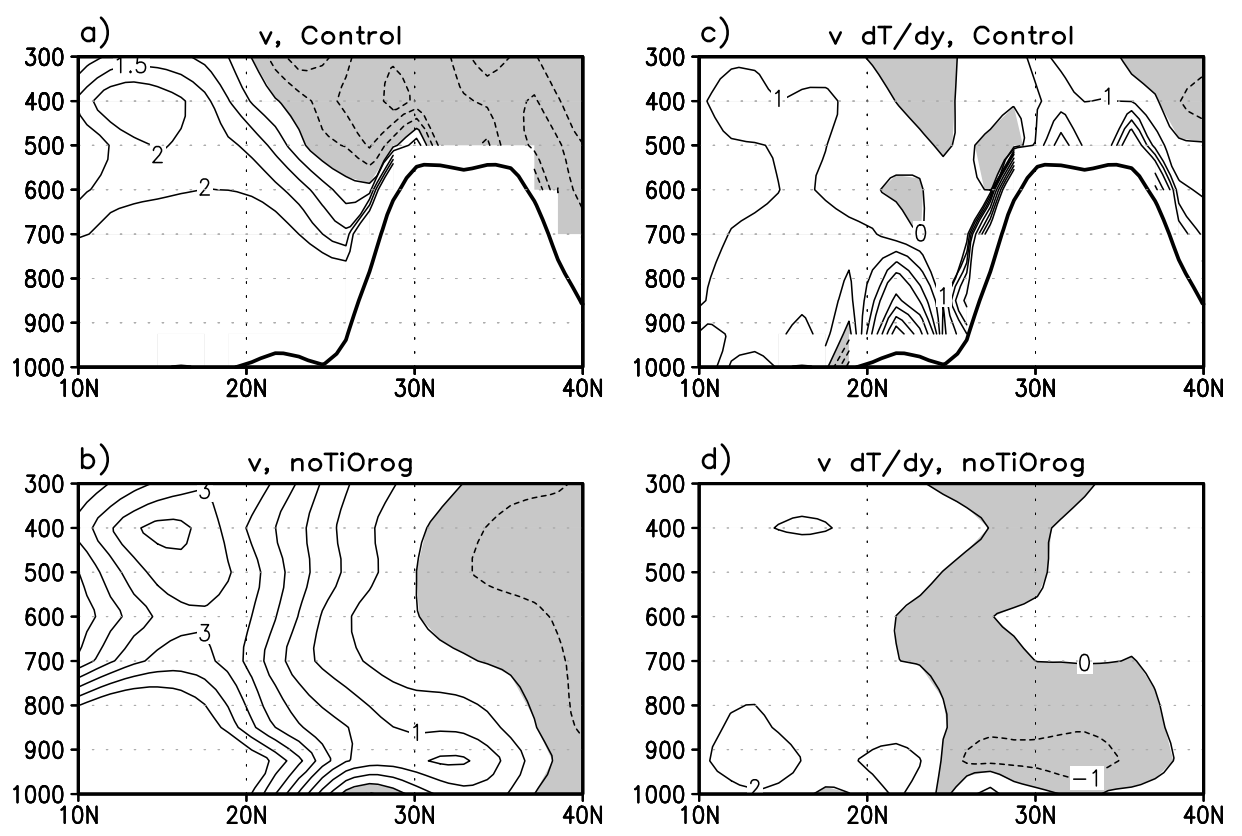

Fig. 13. Vertical profile of meridional velocity from the(a) control and (b) noEhOrog simulations averaged between $85^{\circ}-95^{\circ} \mathrm{E}$. Vertical profiles of temperature (energy) advection from the(c) control and (d) noEhOrog simulations are shown for the same region. 
a) Daily Precipitation, Indian Region

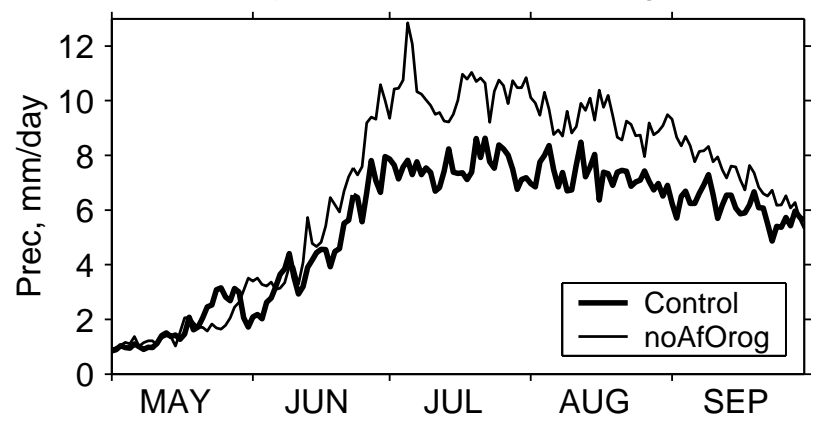

b) Moist Static Energy, Indian Region

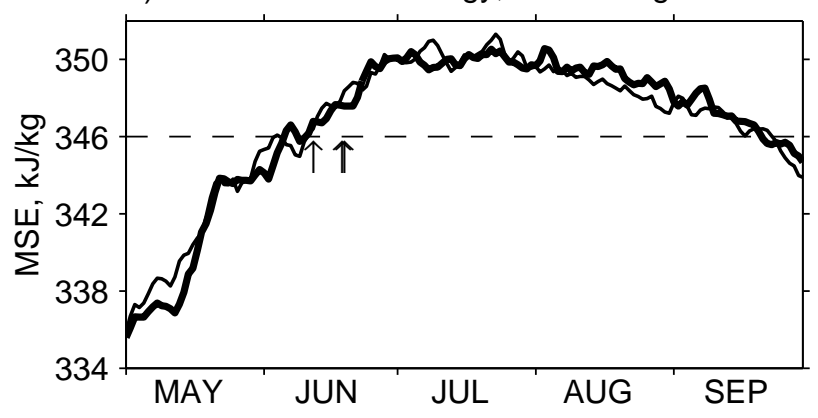

Fig. 14. Evolution of (a) precipitation and (b) moist static energy in control and noAfOrog simulations.

air flow towards the Indian region is more in the noAfOrog simulation as compared to that in the control. The larger mass convergence leads to larger moisture convergence as this air mass traverses over the Arabian Sea. (b) The larger moisture convergence enhances the strength of the Indian monsoon, and the stronger monsoon has a positive feedback on the winds over the Arabian Sea (Srinivasan and Nanjundiah, 2002), resulting in a further increase in moisture convergence and strengthening of the Indian monsoon by $28 \%$ vis-a-vis control. The absence of African orography did not have a large effect on the onset date of all Indian monsoons (Fig. 14a). This is consistent with the near simultaneous attainment of the threshold value of SMSE (Fig. 14b).

\section{Presence of African orography alone}

We found that the absence of global orography reduces the ISMR, but if African orography alone is absent, ISMR increases. We examine now what happens if only African orography is present (prAfOrog) and the orography over the rest of the globe is removed. In this simulation rainfall is lower than both the control and noGlOrog simulations (Fig. 15).

The lower rainfall in prAfOrog during June, July and August is related to the delay in the onset. The onset in prAfOrog occurs during mid-August, even later than in

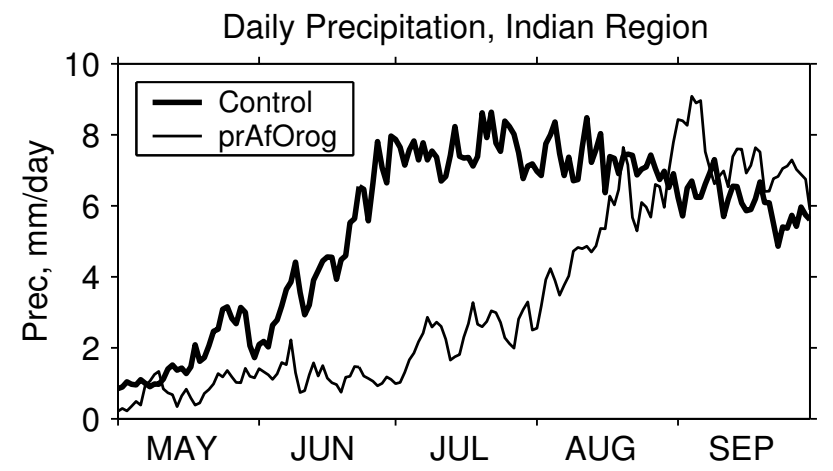

Fig. 15. Evolution of rainfall in the control and prAfOrog simulations.

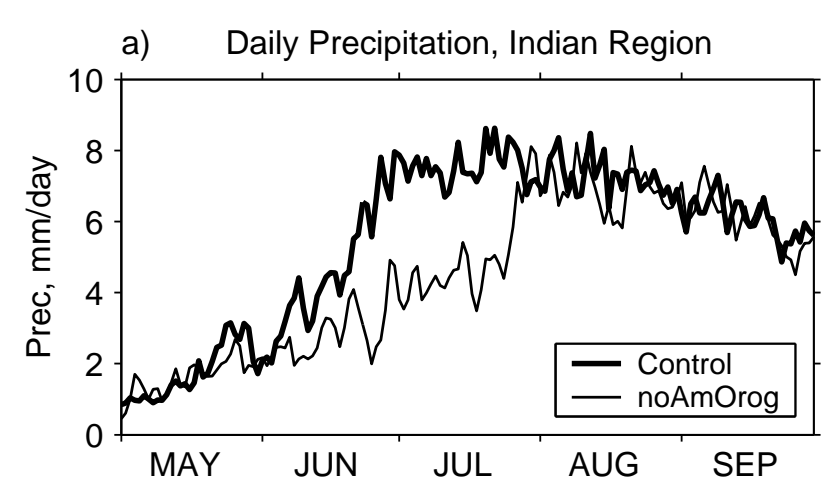

b) Moist Static Energy, Indian Region

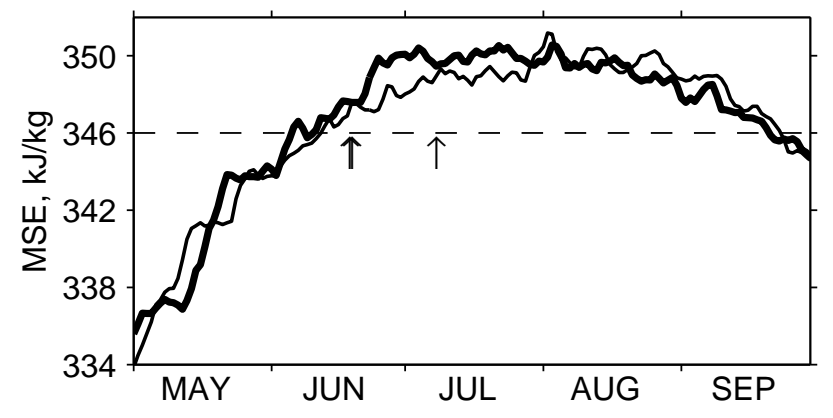

Fig. 16. Evolution of (a) precipitation and (b) moist static energy in the control and noAmOrog simulations.

noGlOrog (mid-July). This delay reduces the seasonal mean rainfall. It is related to the delay in the conditioning of the atmosphere indicated by the delay in the SMSE reaching its threshold value and in the change from large-scale descent to ascent. Both these events in prAfOrog occur later than in noGlOrog. The moisture budget also shows that the net moisture flux is lower than the control by about $4 \mathrm{~mm} \mathrm{day}^{-1}$, the major difference being in the zonal convergence. This reduction in the zonal convergence of moisture flux reduces 


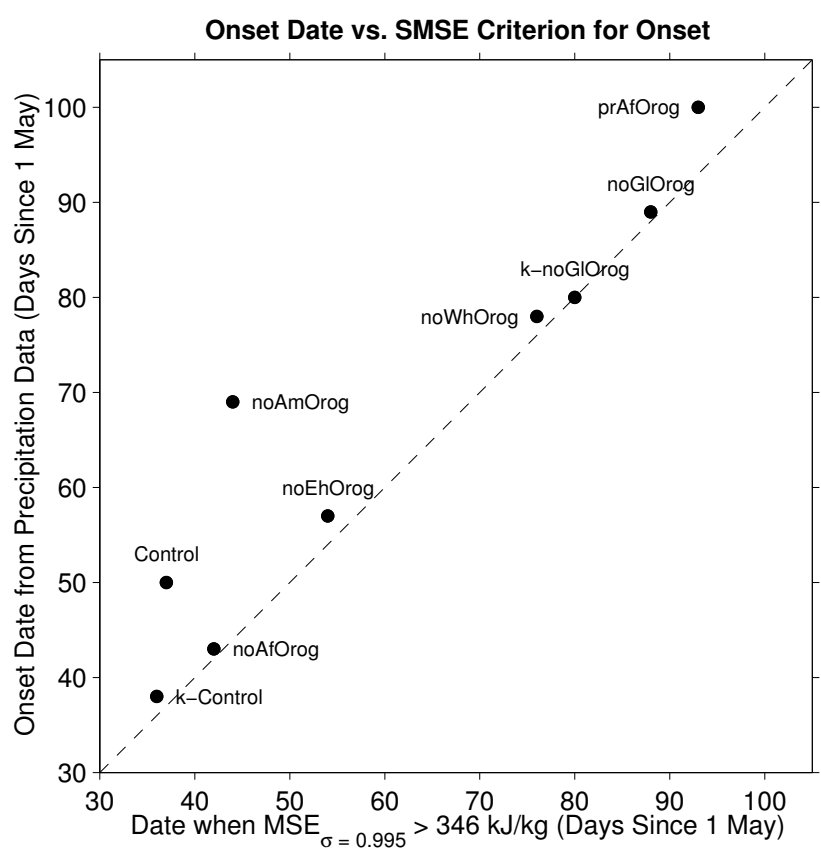

Fig. 17. Onset date vs. first necessary (SMSE) criterion for onset. Key words starting with $k$ - indicates simulation with Kuo cumulus convection.

the SMSE and hence delayes the date of its attainment of the threshold.

\section{Removal of American orography}

We next discuss the impact of the removal of a more remote orography, viz. the orography over the American (both South and North American) region. We find that removal of this orography has a significant impact on the ISMR onset. The onset is delayed by about 20 days in comparison to the control (Fig. 16a). Comparing the evolution of SMSE (Fig. 16b), we notice that noAmOrog reaches this threshold about a week later than the control but the onset is delayed by about 20 days. If we compare the date of onset with date when the SMSE is reached in all the simulations (Fig. 17) we notice that except for noAmOrog in all other simulations, onset occurs soon after the SMSE threshold is reached. Thus, noAmOrog seems to be an exception.

This obviously indicates that SMSE, while a necessary condition, may not be sufficient to determine the onset. It essentially is a thermodynamic parameter that indicates the "conditioning" of the atmosphere, i.e. its amenability to the onset. Since onset also implies changes in large-scale circulation, we next investigate the role of vertical velocity in determining the onset.

\section{Vertical Velocity (Shaded Upward) Indian Region}
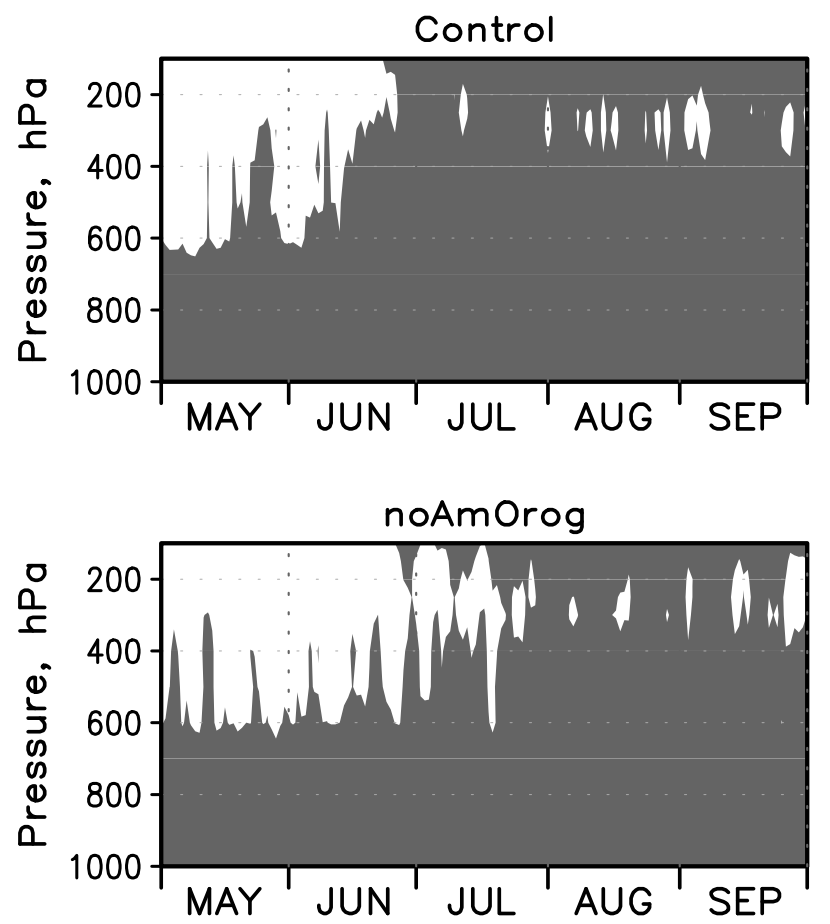

Fig. 18. Vertical profile of vertical velocity over the Indian landmass in control and noAmOrog simulations. Shaded regions indicate upward motion and non-shaded downward motion.

\section{Role of vertical velocity}

We first compare the evolution of vertical velocity in the control and noAmOrog simulations (Fig. 18). We notice that organized large-scale upward motion (up to $500 \mathrm{hPa}$ ) occurs in the control soon after the SMSE crosses the threshold of $346 \mathrm{~kJ} \mathrm{~kg}^{-1}$ and this is followed by the onset of monsoon (as defined in Sect. 5). However, in the noAmOrog simulation this organized large-scale upward motion is noticeably absent until about early July and once the organized large-scale ascent begins, onset occurs. Since the American orography is remote to the Indian monsoon region, its effect can only be felt through upper level circulation (as lower level circulation is usually dominated by local effects).

To investigate the reason for the higher downward motion in the upper troposphere in the noAmOrog simulation as compared to control, the difference in the vertical pressure velocity in the Northern Hemisphere at $500 \mathrm{hPa}$ between control and noAmOrog simulations for the month of May is shown in Fig. 19. A positive relative velocity (shaded regions) in this figure indicates relative downward motion for the noAmOrog simulations as compared to the control in this pre-monsoon month over the South Asian region. A chain of anomalous positive and negative pressure velocity regions 
Pressure Velocity, noAm0rog - Control, $500 \mathrm{hPa}$, May98

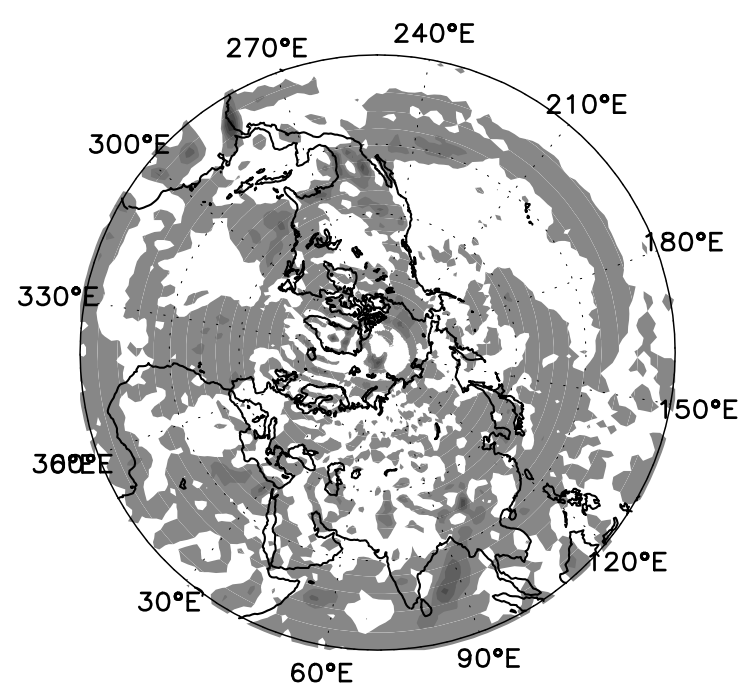

Fig. 19. Difference in $500 \mathrm{hPa}$ vertical pressure velocities between the control and noAmOrog simulations. Shaded regions show relative positive velocity for the noAmOrog simulation and therefore more downward motion at the mid-troposphere.

can be noticed around the globe. This indicates a shift in the position of the Rossby wave pattern. Over the Indian region and Bay of Bengal, relative downward velocity can be noticed from this figure with the removal of American orography. This indicates an anomalous higher convergence over the Indian Region in the upper troposphere. It was found that over most of the northern Indian Ocean, Bay of Bengal, southern parts of the peninsular India and over the northern and western parts of India, the divergence from noAmOrog was less than that of the control in May (not shown). An anomalous positive convergence at the upper troposphere resulted in an anomalous downward motion. This anomalous downward motion at the upper troposphere suppressed the upward motion of the lower troposphere and delayed the onset of the monsoon in the noAmOrog simulation over the Indian region. Joseph and Srinivasan (1999) have also shown that a southerly flow at upper level over the Indian monsoon region related to the displacement of the Rossby wave pattern reduces the strength of the monsoon.

We notice that the onset occurs a few days after SMSE crosses the threshold and a large-scale upward motion begins in other simulations, as well (Fig. 20 for the noGlOrog simulation). However, the lag between the occurrence of these two is strikingly large only in the noAmOrog simulation. This clearly suggests that both the crossing of the SMSE threshold and the occurrence of an organized largescale ascent are required for the onset of the Indian summer monsoon. Figure 21 shows the date when the vertical veloc-

\section{Vertical Velocity (Shaded Upward) Indian Region}
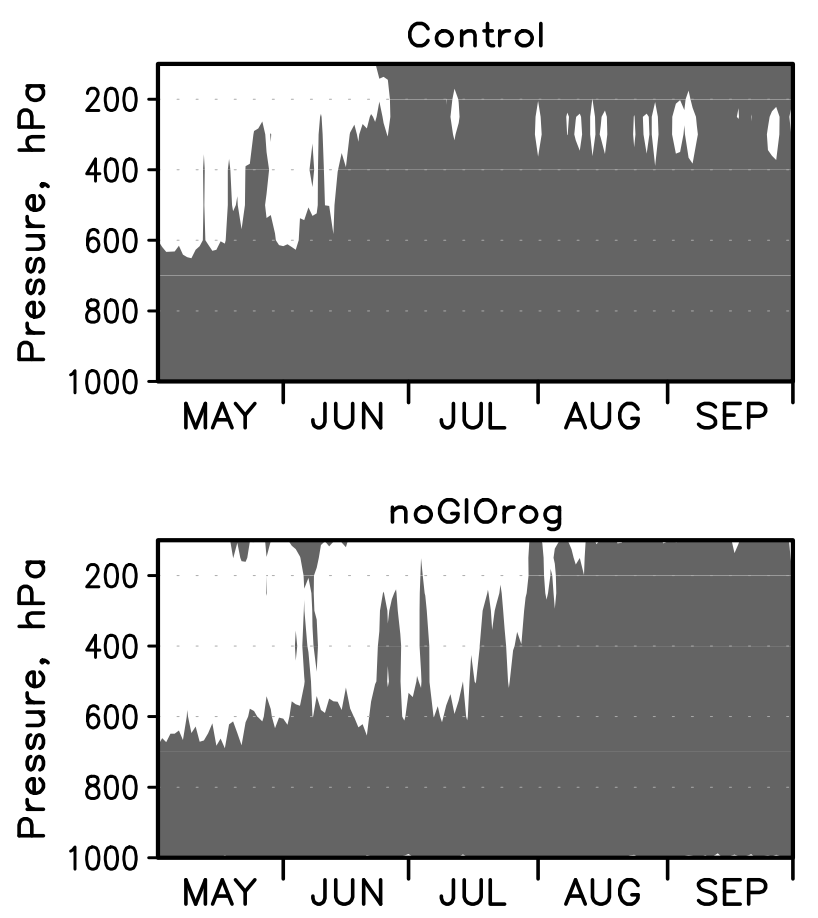

Fig. 20. Vertical Velocity over Indian region in control and noGlOrog simulations.

ity at $500 \mathrm{hPa}$ became upward for the first time in the season over the Indian region, as a function of the change in the onset date derived from the precipitation criteria. We find that in all the cases the vertical velocity criteria (second necessary condition) was satisfied earlier than the onset of monsoon precipitation over this region. Moreover, if we compare the dates of onset of all the simulations with the dates when both the criteria are satisfied, we find a better correspondence (shown in Fig. 22) than when only one of the threshold criteria is used (Fig. 17 or Fig. 21). Thus, it can be said that while the SMSE threshold is a necessary condition, the occurrence of a organized large-scale ascent is also another important and necessary condition. This is consistent with a recent observational study of Zhang et al. (2004), who showed that both thermodynamic and dynamic quantities are important to explain the onset of the south Asian summer monsoon.

\section{Results from Kuo convection scheme and observa- tions}

We have performed ensemble simulations of control and perturbed experiments with Kuo cumulus convection (Anthes, 


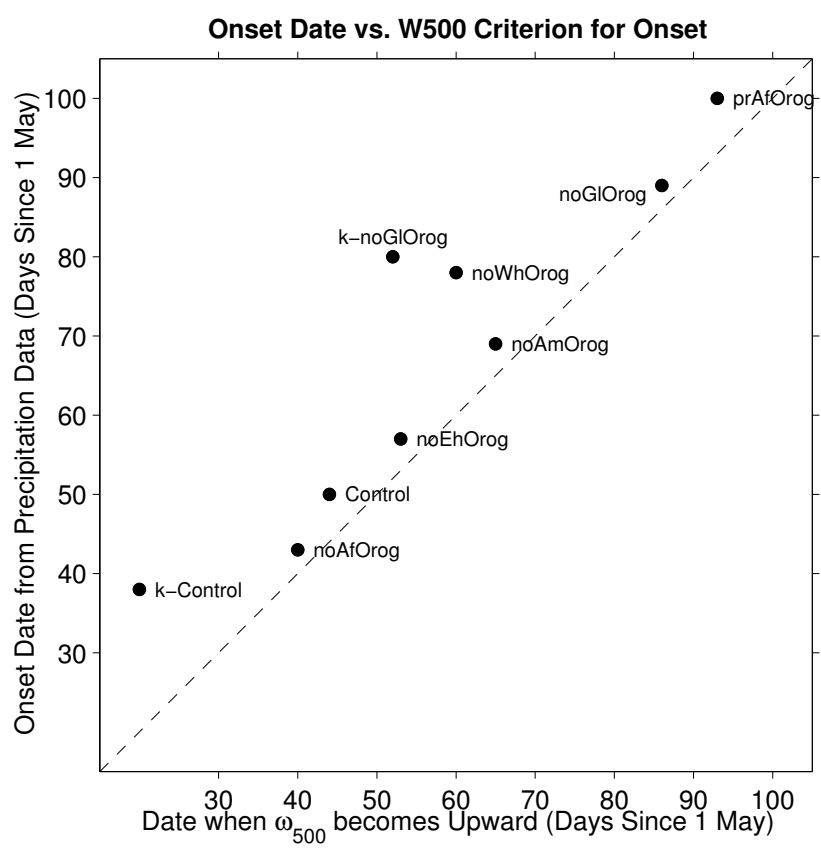

Fig. 21. Onset date vs. second necessary criterion (W500) for onset. Key words starting with $k$ - indicates simulation with Kuo cumulus convection.

1977), as well, to test the robustness of the result obtained here with the convection scheme used in the model. In Figs. 17, 21, and 22 we have shown the onset dates for the control and noGlOrog simulations with Kuo convection, as well (k-Control and k-noGlOrog). Monsoon onset was delayed by 42 days over this region with the removal of global orography. An examination of the SMSE and vertical velocity criteria at $500 \mathrm{hPa}$ showed that this delay can be explained for Kuo convection, as well, similar to the SAS convection results. It was noticed that both these necessary criteria were responsible for the delay in onset in the noGlOrog simulation. Onset occured only on or before both criteria were satisfied over this region.

To test the monsoon onset hyphothesis with actual observations, we have considered two extreme adjacent years, viz. 2003 and 2004 , for which the all-India $\left(70^{\circ}-90^{\circ} \mathrm{E}, 5^{\circ}-25^{\circ} \mathrm{N}\right.$, land part) monsoon onset dates were separated by 29 days. Figure 23a shows the time series of precipitation from GPCP (Huffman et al., 2001) over this region. A 5-day running mean smoother was applied to the data, to reduce the large day-to-day oscillations. To test our theory, we have taken moist static energy at $2 \mathrm{~m}$ above the ground level and vertical velocity at $500 \mathrm{hPa}$ from the NCEP/NCAR reanalysis data set (Kalnay et al., 1993). Figure 23b shows that the MSE at $2 \mathrm{~m}$ crosses a certain threshold (here $338 \mathrm{~kJ} \mathrm{~kg}^{-1}$ ) before the precipitation onset. (Note that this threshold is different than the threshold used for the model. The reason is two fold. Firstly, the levels of both the data set are not same. For model

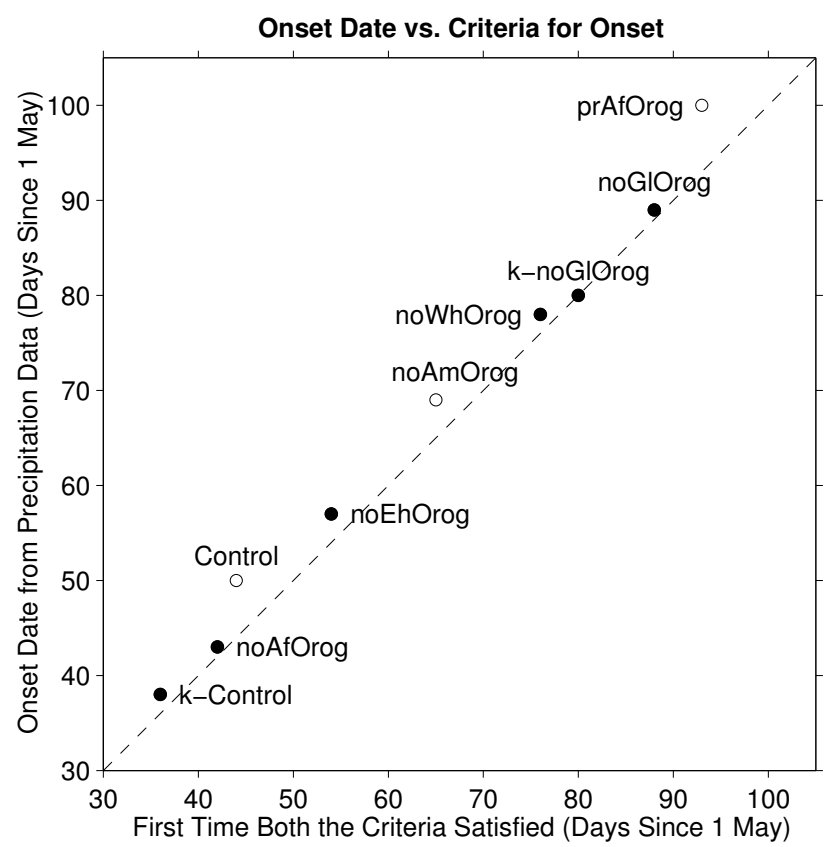

Fig. 22. Onset date vs. the dates when both the criteria of SMSE threshold and organized upward ascent are satisfied. For the simulations marked with filled (open) circle the first (second) necessary criterion was satisfied later than the second (first) criterion. Key words starting with $k$ - indicates simulation with Kuo cumulus convection.

results we use data at the lowest model layer $-\sigma=0.995$ - but for observation, due to the unavailability of data, we use $2 \mathrm{~m}$. Secondly, due to presence of bias in the model, its threshold can be different than that in the observed data. However, these thresholds should not vary from one simulation to the other in the model and from one year to the other in the observations.) Moist static energy crossed this threshold 10 and 5 days before the onset of precipitation during 2003 and 2004, respectively. The vertical velocity criterion was more restrictive compared to the MSE criterion during 2003 (not shown). In other words, in this year the vertical velocity at $500 \mathrm{hPa}$ became upward later than MSE at $2 \mathrm{~m}$ whwn it crossed its threshold. However, both the criteria were satisfied on or before the precipitation onset over the Indian region (Fig. 23c) during these years.

\section{Discussions}

In the preceding sections we have discussed the impact of orography over various regions of the world on the onset of Indian Summer Monsoon. With the exception of African orography, removal of all other orography delays the onset and weakens the seasonal mean rainfall over the Indian region. The changes in the date of onset in all the cases discussed above can be explained through changes in static 
Precipitation and Criteria for Onset, 70-90E, 5-25N, Land a) GPCP Precipitation

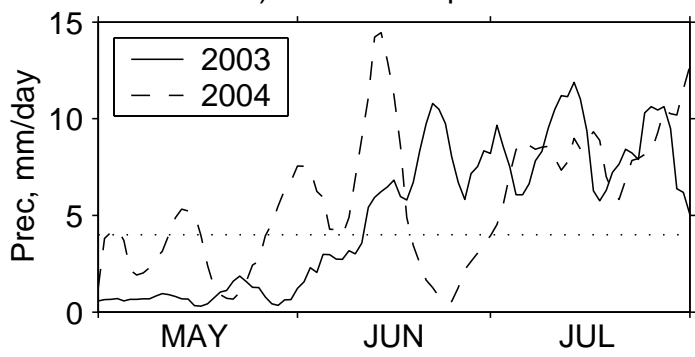

b) NCEP MSE at $2 \mathrm{~m}$

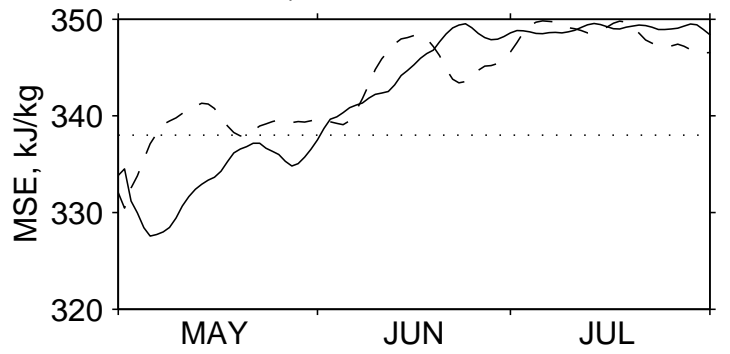

c) Onset Date vs. Both Criteria

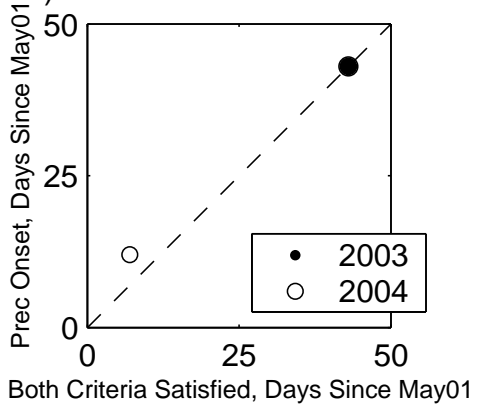

Fig. 23. Precipitation onset date vs. moist static energy and vertical velocity criteria for the onset in observation-based data over the region $70^{\circ}-90^{\circ} \mathrm{E}, 5^{\circ}-25^{\circ} \mathrm{N}$ (land part) during 2003 and 2004 (all-India onset was substantially delayed in 2003 as compared to 2004.) (a) time series of GPCP (Huffman et al., 2001) precipitation. (b) time series of moist static energy at $2 \mathrm{~m}$. (c) onset date vs. the day when both the criteria were satisfied.

stability (represented by surface MSE) and large-scale convergence (represented by vertical ascent). The static stability is a necessary conditioning parameter and the large-scale deep ascent reaching up to $500 \mathrm{hPa}$ is the trigger (the two necessary conditions) for the occurrence of the onset.

Using only stability as a parameter to determine onset, we find that reaching the threshold of $346 \mathrm{~kJ} \mathrm{~kg}^{-1}$ does not guarantee the occurrence of onset, as can be seen (Fig. 17). This threshold is reached a few weeks earlier in some cases, such as the noAmOrog simulation. We also find that in some cases though a large-scale organized ascent precedes satisfying the SMSE (notably noEhOrog), the onset as defined by the rainfall criteria, occurs only after both criteria of SMSE cross- ing the $346 \mathrm{~kJ} \mathrm{~kg}^{-1}$ and the occurrence of organized vertical ascent over the Indian region (Fig. 22) have been satisfied. Either of them alone does not indicate the onset. On average, we find that the onset occurs within 5-6 days of both criteria being satisfied. In other words, occurrence of largescale convergence cannot be sustained in the absence of a conditional, unstable atmosphere, while reaching the stability threshold itself does not cause the onset to occur, onset occurs only when both conditions are satisfied.

\section{Conclusions}

We have studied the impact of the removal of orography over different regions of the globe on the onset of the Indian summer monsoon in a GCM. With the exception of African orography, the absence of orography reduces the strength of the ISMR caused by the delay in onset date. However, once the onset occurs, the intensity of rainfall (using daily rainfall as a yardstick) is unaffected by orography. We also find that West Himalayan orography has a greater impact than the East Himalayan orography on the onset and strength of the ISMR. However on smaller regional scales, such as that of West Central India or North East India, the impact is different. Onset is earliest in noAfOrog. Absence of African orography does not significantly change the onset date. It modulates the strength of the Indian summer monsoon through changes in mass and moisture convergence and related positive feedbacks and the winds over the Arabian Sea. Maximum delay is discernible in the simulation in which only African orography is present. The changes in onset dates has been explained using two criteria: (a) the instability of the atmosphere which is a conditioning parameter and (b) the occurrence of largescale convergence. The reaching of a stability threshold (as measured by a threshold in SMSE) and the occurrence of large-scale ascent causes the onset of ISMR. We find that West Himalayan orography has a more significant impact on the onset date. The West Himalayan orography acts as a barrier for the cold winds from the upper-latitudes and in the absence of the cold winds, the atmosphere reaches the critical threshold of the instability earlier. The presence of East Himalayan orography strengthens the large-scale, low-level ascent but this does not develop into a deep convection over the entire Indian region until the stability criteria is satisfied. In essence, the instability of the atmosphere is the conditioning parameter (or the first necessary condition) while the occurrence of an organized, deep, large-scale ascent is the trigger (or the second necessary condition). The occurrence of both leads to the onset of the Indian Summer Monsoon.

Our results are somewhat similar to that obtained by Chao (2000). He has shown that the onset over the Indian region can occur without mid-atmosphere heating by the Tibetan Plateau, and it depends on the instability of the atmosphere set by the north-south SST gradient. Our simulation without West and East Himalayan orography supports this. 
We have also shown that surface moist static energy is closely related to the vertical instability (convective available potential energy, or CAPE) and has to cross a certain threshold for the onset to occur.

In the present study we have addressed the issue of onset of Indian summer monsoon. The impact of orography on the onset of monsoons over other regions will be the subject of future study. Further, these studies should be performed using a coupled model, to understand the combined effects of orography and atmosphere-land-ocean coupling.

Acknowledgements. Topical Editor F. D'Andrea thanks two referees for their help in evaluating this paper.

\section{References}

Anthes, R. A.: A cumulus parameterization scheme utilizing a onedimensional cloud model, Mon. Weather Rev., 105, 270-286, 1977.

Chakraborty, A., Nanjundiah, R., and Srinivasan, J.: Role of Asian and African orography on Indian summer monsoon., Geophys. Res. Lett., 29, doi:10.1029/2002GL015522, 2002.

Chao, W. C.: Multiple quasi equilibria of the ITCZ and the origin of monsoon onset, J. Atmos. Sci., 57, 641-652, 2000.

Fasullo, J. and Webster, P. J.: A hydrological definition of Indian monsoon onset and withdrawal, J. Climate, 16, 3200-3211, 2003.

Fels, S. B. and Schwarzkopf, D.: An efficient, accurate algorithm for calculating $\mathrm{CO}_{2} 15 \mu \mathrm{m}$ band cooling rates., J. Geophys. Res., 86(C2), 1205-1232, 1981.

Grell, G. A.: Prognostic evaluation of assumptions used by cumulus parameterization., Mon. Weather Rev., 121, 764-787, 1993.

Hahn, D. G. and Manabe, S.: The role of mountains in the south Asian monsoon circulation., J. Atmos. Sci., 32, 1515-1541, 1975.

He, H., Sui, C.-H., Jian, M., Wen, Z., and Lan, G.: The evolution of tropospheric temperature field and its relationship with the onset of Asian summer monsoon, J. Meteorol. Soc. Japan, 81, 12011223, 2003.

Hoskins, B. J. and Rodwell, M. J.: A model of the Asian summer monsoon. Part I: The global scale, J. Atmos. Sci., 52, 1329-1340, 1995.

Huffman, G. J., Adler, R. F., Morrissey, M. M., Bolvin, D. T., Curtis, S., Joyce, R., McGavock, B., and Susskind, J.: Global precipitation at one-degree daily resolution from multisatellite observations., J. Hydro Meteor., 2, 36-50, 2001.

Iribarne, J. and Godson, W.: Atmospheric Thermodynamics, D. Reidel Pub. Co., 1973.

Janowiak, J. and Xie, P.: A global scale examination of monsoon related precipitation, J. Climate, 16, 4121-4133, 2003.

Joseph, P. and Srinivasan, J.: Rossby waves in may and the Indian summer monsoon rainfall, Tellus, 51, 854-859, 1999.

Kalnay, E., Kanamitsu, M., Kistler, R., Collins, W., Deaven, D., Gandin, L., Iredell, M., Saha, S., White, G., Woollen, J., Zhu, Y., Chelliah, M., Ebisuzaki, W., Higgins, W., Janowiak, J., Mo, K. C., Ropelewski, C., Wang, J., Leetmaa, A., Reynolds, R., Jenne, R., and Joseph, D.: The NCEP/NCAR 40-year reanalysis project, Bull. Amer. Meteorol. Soc., 77, 764-787, 1993.
Kanae, S., Oki, T., and Musiake, K., Principal condition for earliest Asian summer monsoon onset, Geophys. Res. Lett., 29, doi:10.1029/2002GL015346, 2002.

Kawamura, R., Fukuta, Y., and Ueda, H.: A mechanism of the onset of the Australian summer monsoon, Geophys. Res. Lett., 107, doi:10.1029/2001JD001070, 2002.

Kitoh, A.: Effects of large-scale mountains on surface climate a coupled ocean-atmosphere general circulation model study, J. Meteorol. Soc. Japan, 80, 1165-1181, 2002.

Krishnakumar, V. and Lau, K. M.: Possible role of symmetric instability in the onset and abrupt transition of the Asian monsoon, J. Meteorol. Soc. Japan, 76, 363-383, 1998.

Krishnamurti, T. N., Molinari, J., and Pan, H. L.: Numerical simulation of the Somali jet, J. Atmos. Sci., 33, 2350-2362, 1976.

Lacis, A. A. and Hansen, J. K.: A parameterization for the absorption of solar radiation in the earth's atmosphere., J. Atmos. Sci., 32, 118-133, 1974.

Minoura, D., Kawamura, R., and Matsuura, T.: A mechanism of the onset of the South Asian summer monsoon, J. Meteorol. Soc. Japan, 81, 563-580, 2003.

Nanjundiah, R. and Srinivasan, J.: Anomalies of precipitable watervapor and vertical stability during El-Niño, Geophys. Res. Lett., 26, 95-98, 1999.

Pan, H. L. and Mahrt, L.: Interaction between soil hydrology and boundary layer development, Bound. Layer Meteor., 38, 185202, 1986.

Pierhumbert, R. T.: An essay on the parameterization of orographic wave drag. In Observation, Theory, and Modelling of Orographic Effects, Vol. 1., European Centre for Medium-Range Weather Forecasts, Reading, England, 251-282, 1987.

Reynolds, R. W. and Smith, T. M.: A high-resolution global sea surface temperature climatology., J. Climate, 8, 1571-1583, 1995.

Sashegyi, K. D. and Geisler, J. E.: A linear model study of the cross-equatorial flow forced by summer monsoon heat sources, J. Atmos. Sci., 44, 1706-1722, 1987.

Sela, J. G.: The new NMC operational spectral model, Eighth conference on numerical weather prediction, February 22-26, Baltimore, Maryland, 1988.

Srinivasan, J. and Nanjundiah, R. S.: The evolution of Indian summer monsoon in 1997 and 1983, Meteorol. Atmos. Phys., 79, 243-257, 2002.

Wang, B. and Lin, H.: Rainy season of the Asian-Pacific summer monsoon, J. Climate, 15, 386-398, 2002.

Xie, P. and Arkin, P. A.: A 17-year monthly analysis based on gauge observations, satellite estimates and numerical model outputs, Bull. Amer. Meteorol. Soc., 78, 2539-2558, 1997.

Xie, S. P. and Saiki, N.: Abrupt onset and slow seasonal evolution of summer monsoon in an idealized GCM simulation, J. Meteorol. Soc. Japan, 77, 949-968, 1999.

Yanai, M., Li, C., and Song, Z.: Seasonal heating of the Tibetan Plateau and its effects on the evolution of the Asian summer monsoon, J. Meteorol. Soc. Japan, 70, 319-351, 1992.

Yano, J. I. and McBride, J. L., An aquaplanet monsoon, J. Atmos. Sci., 55, 1373-1399, 1998.

Zhang, Z., Chan, J. C. L., and Ding, Y.: Characteristics, evolution and mechanisms of the summer monsoon onset over southeast Asia., Int. J. Climatol., 24, 1461-1482, 2004. 